\title{
AS ATITUDES DOS ESTUDANTES FACE À AVALIAÇÃO DAS INSTITUIÇÕES DE ENSINO SUPERIOR
}

\author{
Sónia CARDOSO* \\ RuI SANTIAGO** \\ ClÁUdia SARRICo***
}

Recebido em: 01 de novembro de 2009

Aprovado em: 21 de julho de 2010

\begin{abstract}
*Investigadora do Gabinete de Análise e Desenvolvimento da Agência de Avaliação e Acreditação do Ensino Superior, Lisboa, Portugal e Investigadora do Centro de Investigação em Políticas de Ensino Superior, Matosinhos, Portugal. E-mail: scardoso@ua.pt.

**Professor Associado com Agregação da Secção Autónoma das Ciências Sociais, Jurídicas e Políticas da Universidade de Aveiro, Aveiro, Portugal e Investigador do Centro de Investigação em Políticas de Ensino Superior, Matosinhos, Portugal. E-mail: rui.santiago@ua.pt

***Professora Auxiliar da Secção Autónoma das Ciências Sociais, Jurídicas e Políticas da Universidade de Aveiro, Aveiro, Portugal e Investigadora do Centro de Investigação em Políticas de Ensino Superior, Matosinhos, Portugal. E-mail: c.s.sarrico@ua.pt
\end{abstract}

Resumo: Apesar da sua importância para a avaliação das instituições de ensino superior, os estudantes parecem não constituir, ainda, um objecto de estudo relevante no campo da investigação sobre este processo de regulação institucional. Reconhecendo esta lacuna, o presente estudo pretende, através da análise das representações que os estudantes elaboram deste processo, indagar sobre os contornos que emolduram as suas atitudes relativamente ao mesmo. Recorre, neste sentido, ao enquadramento metodológico e aos resultados empíricos de uma investigação mais abrangente, que tem por objecto a análise do conteúdo das representações estudantis da avaliação das instituições de ensino superior. A análise dos resultados permite concluir que os estudantes assumem atitudes tendencialmente positivas face à noção e à implementação da avaliação, como resultado da legitimidade que lhe reconhecem. Esta legitimidade surge, por sua vez, conectada, essencialmente, com razões instrumentais, ligadas ao incremento da qualidade das instituições, dos cursos e da docência e, em última instância, à promoção da integração dos futuros graduados no mercado de trabalho.

Palavras-chave: Ensino superior. Avaliação. Estudantes. Representações estudantis. Portugal.

\section{STUDENTS' ATTITUDES TOWARDS HIGHER EDUCATION INSTITUTIONS' EVALUATION}

Abstract: Despite their relevance to the evaluation of higher education institutions, students still do not seem to constitute a relevant study subject in the research field of this regulation process. Aware of this gap, the present study intends to, through the analysis of the social representations that students elaborate on this process, examine the features framing their attitudes towards it. It resorts, in this sense, to the methodological framework and to the empirical findings of a broader research, having as subject the analysis of students' social representations on the evaluation of higher education institutions. The analysis of the results allows for the conclusion that students tend to assume positive attitudes towards the notion and the implementation of evaluation, as a result of the legitimacy they recognize to it. This legitimacy emerges, in its turn, essentially connected with instrumental reasons, linked to the increase of the quality of institutions, degrees and teaching and, ultimately, to the future insertion of graduates in the labour market.

Key words: Higher education. Evaluation. Students. Students' representations. Portugal. 


\section{INTRODUÇÃO}

A centralidade crescente assumida pela avaliação das instituições de ensino superior tem sido acompanhada por um proliferante número de investigações em que esta temática emerge como objecto de estudo privilegiado. Porém, o estudo sobre os estudantes constitui-se, neste domínio, como uma área de investigação relativamente "silenciosa" (JOHNSON; DEEM, 2003), em especial no que respeita ao modo como se relacionam e posicionam relativamente ao objecto "avaliação" (JOHNSON; DEEM, 2003; LEITE et al., 2006; NASSER; FRESKO, 2002; STENSAKER et al., 2008; WESTERHEIJDEN; HULPIAU; WAEYTENS, 2007). Assim, embora possam ser encontrados trabalhos que afloram, ainda que indirectamente, as configurações assumidas pela relação dos estudantes com a avaliação (GREEN et al., 1995; HARVEY, 2003; LECKEY; NEILL, 2001; POWELL; HUNT, IRVING, 1997), é possível constatar, também, que a forma como "realmente" a perspectivam "permanece ainda uma questão sem uma resposta empírica" (WESTERHEIJDEN; HULPIAU; WAEYTENS, 2007, p. 309). Esta "ausência", particularmente evidente para o caso português, parece justificar, a nosso ver, o desenvolvimento de uma abordagem mais pormenorizada sobre esta mesma temática. Assume-se, neste contexto, que tal abordagem pode ser permitida, especificamente, pela análise das atitudes que os estudantes expressam em relação à avaliação das instituições de ensino superior.

Assim, tomando por referência o contexto nacional, a questão orientadora do presente estudo pode ser enunciada da seguinte forma: Que orientações ou posições assumem os estudantes relativamente ao conceito e implementação da avaliação das instituições?

Pretendendo responder a esta questão, o trabalho encontra-se organizado em cinco partes. Na primeira, procura-se caracterizar, sucintamente, os principais traços que configuram a avaliação das instituições de ensino superior portuguesas, tal como esta foi definida pelo sistema de avaliação formalizado nos anos noventa (Lei 38/94) e em operação por cerca de uma década (19952005). Ainda neste contexto, intenta-se elucidar o papel desempenhado pelos estudantes nos exercícios de implementação "no terreno" da avaliação.

Enformada pela teoria das representações sociais e com base na assunção de que a relação dos estudantes com a avaliação pode ser apreendida através da análise do modo como a representam, a segunda parte deste trabalho tem como principal enfoque um esforço de operacionalização do conceito de representação estudantil da avaliação. Salienta-se, neste âmbito, a importância de analisar, mais aprofundadamente, uma das principais dimensões que compõem o conteúdo destas representações: as atitudes. 
Em seguida, recorrendo à abordagem metodológica que enforma um estudo mais global sobre o modo como os estudantes representam a avaliação das instituições de ensino superior, descrevem-se os procedimentos metodológicos que sustentam o presente trabalho. Subsequentemente, são apresentados e discutidos os principais resultados empíricos que permitem responder à questão de partida que o orienta, isto é, que possibilitam a caracterização das atitudes dos estudantes face à avaliação. Na última parte do trabalho são apresentadas, de modo sumário, as principais conclusões permitidas por esta mesma caracterização, salientando a ambiguidade que molda tais atitudes.

\section{A AVALIAÇÃO DAS INSTITUIÇÕES DE ENSINO SUPERIOR}

Embora mais tardiamente que a maioria dos países da Europa Ocidental, Portugal assiste, a partir de meados da década de noventa, à emergência da avaliação enquanto instrumento "pós-burocrático" central de regulação pelo Estado do desempenho do sistema e das instituições de ensino superior (AFONSO, 1998; MAGALHÃES, 2004; ROSA, 2003; ROSA; SARAIVA; DIZ, 2005). Inspirado, sobretudo, no modelo avaliativo holandês, o sistema nacional de avaliação então ${ }^{1}$ definido (Lei 38/94) pode, sucintamente, ser caracterizado como: (i) sustentado numa perspectiva de melhoria da qualidade das instituições; (ii) centrado, essencialmente, nos cursos de graduação; (iii) escorado num modelo formativo de avaliação, i.e. focado, simultaneamente, nos processos e resultados institucionais; (iv) detendo um carácter nacional (todas as instituições nacionais), compreensivo (todos os cursos de graduação e respectivas áreas científicas) e periódico (ciclos de avaliação de cinco anos); (v) sincronizado por um órgão coordenador - o CNAVES (Conselho Nacional de Avaliação do Ensino Superior) - e estruturado em dois momentos ou fases - a auto-avaliação (pelas instituições) e a avaliação externa (por equipas de peritos) - seguidos da publicação dos relatórios externos de avaliação.

Emoldurados por estas características, dois ciclos de avaliação tiveram lugar: um, entre 1995 e 2000, apenas com a presença das universidades públicas; e, outro, entre 2000 e 2005, já com todas as instituições de ensino superior, i.e. universidades e politécnicos públicos e instituições universitárias e politécnicas privadas. Estes dois ciclos envolveram a participação de vários actores, diferentemente posicionados face às instituições e à implementação da avaliação.

1 Após a sua criação, o sistema de avaliação Português foi sendo alvo de algumas iniciativas legislativas, com o objectivo de o modificar. Estas iniciativas vieram a desembocar, em 2007, na extinção formal deste sistema, quando, devido, entre outros factores, à pressão de tendências verificadas ao nível da Europa, foi substituído por um novo sistema de avaliação e acreditação (Lei 38/2007). 
Apesar de, num contexto algo ambíguo, combinando a sua conceptualização enquanto "clientes" ou "consumidores" com a de actores "institucionais-chave" (CARDOSO; CARVALHO; SANTIAGO, 2007), os estudantes eram perspectivados como um dos grupos fundamentais com participação no desenvolvimento da avaliação. Tal devia-se à assunção de que estes actores eram os mais interessados e, em última instância, os mais afectados pelas dimensões institucionais em avaliação e de que ocupavam, além disso, uma posição privilegiada para fornecer informação crítica sobre estas mesmas dimensões. Consequentemente, a participação dos estudantes estava prevista, em simultâneo, nos dois principais níveis da avaliação: na sua definição e coordenação política e nas suas fases de implementação institucional (auto-avaliação e avaliação externa).

Ao nível da definição e coordenação politica, a participação dos estudantes materializava-se, especificamente, na sua representação em dois principais órgãos: os conselhos que representavam as instituições no processo de avaliação; e o órgão coordenador responsável pela definição estratégica da avaliação dos cursos - o CNAVES (CNAVES, 2006; OLIVEIRA; VEIGA SIMÃO, 2002). No primeiro caso, previa-se que os estudantes (dois por cada conselho, seleccionados a partir das associações de estudantes) participassem, por exemplo: nas discussões destinadas à estruturação dos guiões de auto-avaliação e avaliação externa; na definição da composição e actividade das equipas de avaliação; ou, ainda, no planeamento dos ciclos avaliativos. No segundo caso, a integração dos estudantes (três, eleitos, respectivamente, a partir das associações de estudantes das universidades e politécnicos públicos e das instituições privadas), visava promover a monitorização do processo de avaliação e a proposta de sugestões com o objectivo de "o dinamizar e melhorar" (OLIVEIRA; VEIGA SIMÃO, 2002, p. 106). Contudo, os estudantes não integravam as equipas de avaliação externa. Estas eram, exclusivamente, constituídas por especialistas "acreditados", que detinham posições profissionais, académicas ou científicas relevantes.

Embora mais representativa, por supostamente compreender o total dos estudantes de cada curso de graduação sob escrutínio, a participação dos estudantes nas fases de implementação da avaliação assumia formas menos activas do que as anteriormente descritas. Esta participação traduzia-se, essencialmente, na auto-avaliação, na resposta a questionários e, na avaliação externa, na presença em reuniões com as equipas de peritos. O propósito da integração dos estudantes nestes dois momentos da avaliação consistia em possibilitar a recolha e sistematização de informação pertinente sobre as várias dimensões do funcionamento das instituições e dos cursos de graduação. 
Com base na análise destas formas de participação, é possível concluir que, apesar da sua centralidade para a avaliação (VEIGA SIMÃO; MACHADO DOS SANTOS, 2002), os estudantes eram remetidos, no seu contexto, para papéis de meros informantes "passivos". Esta passividade traduzia-se na sua exclusão face a formas mais activas de intervenção, possibilitadas, por exemplo, pela sua integração nas equipas de auto-avaliação e avaliação externa, ou pela sua colaboração na redacção dos relatórios de avaliação.

Porém, é possível assumir que, não obstante o seu afastamento relativamente a papéis e funções mais "activos" no desenvolvimento da avaliação, os estudantes se constituem como actores capazes de sobre ela reflectir e produzir discursos críticos. Ao fazê-lo, é possível considerar que os estudantes sintetizam e exprimem um conjunto de conhecimentos, significados e percepções que traduzem as posições que assumem face aos diferentes componentes e momentos da avaliação (LEITE et al., 2006; LEITE et al., 2007). De igual modo, é expectável que, nestas posições, seja possível identificar um conjunto de elementos críticos sobre o que "é" a avaliação que, por seu turno, sustentam propostas concretas de (re)orientação sobre o que esta "deve" ser. (LEITE et al., 2006)

O reconhecimento, nos estudantes, de tais capacidades críticas e reflexivas parece, assim, justificar, à luz das lacunas existentes no conhecimento sobre esta temática, o estudo mais aprofundado das posições e significações atribuídas à avaliação por este grupo de actores institucionais. É com o intuito de alcançar tal objectivo que nos propomos a analisar, concretamente, as representações estudantis da avaliação. Na parte subsequente deste trabalho tentamos, precisamente, operacionalizar este conceito recorrendo, para isso, à teoria das representações sociais.

\section{A AVALIAÇÃO DAS INSTITUIÇÕES COMO OBJECTO DE REPRESENTAÇÃO DOS ESTUDANTES}

Surgida na década de sessenta, no seio da psicologia social (BEAUVOIS; DESCHAMPS, 1990; JODELET, 1996, 1997), a teoria das representações sociais constitui uma abordagem teórico-conceptual que se propõe, grosso modo, explicar o processo e dinâmicas de construção do conhecimento sobre a realidade social. Segundo esta abordagem, a realidade e as suas componentes - objectos, sujeitos, conhecimentos, situações, acontecimentos - não têm, per se, um significado fixo, derradeiro ou único. Este é, ao invés, construído, a cada momento, pelos actores vinculados a diferentes grupos sociais, tendo como quadro de referência a variedade de culturas e modos de vida de uma sociedade. 
O conceito de representação social traduz, precisamente, esta ideia de construção social da realidade. Neste sentido, pode ser perspectivado, genericamente, como circunscrevendo o conjunto de significados, conhecimentos, valores, imagens, opiniões socialmente elaborado, transmitido e adquirido, que define cada um dos objectos sociais e que serve de suporte à interpretação e explicação que deles fazem os actores sociais, ao mesmo tempo que significa o modo como estes interagem e se posicionam face a esses mesmos objectos.

Não obstante a possibilidade desta sua operacionalização global, o conceito de representação social é, porém, devido à sua complexidade, passível de múltiplas definições. Entre estas, uma das mais amplamente divulgadas e consensuais no interior da comunidade científica, pela sua abrangência e pela articulação que faz de componentes ou dimensões ao mesmo tempo relacionais, cognitivas, comportamentais, comunicacionais e sócio-culturais, é a de Denise Jodelet (1997). Segundo a autora, as representações sociais podem ser essencialmente definidas como "forma(s) de conhecimento, socialmente elaborada(s) e partilhada(s), tendo um alcance prático e concorrendo para a construção de uma realidade comum a um conjunto social". (JODELET, 1997, p. 53, tradução nossa)

Nesta lógica, as representações sociais constituem-se como modalidades de conhecimento social prático (DE SÁ, 1994; JODELET, 1996; SANTIAGO, 1996), que servem de enquadramento, não só ao modo como os actores (integrados nos grupos sociais) pensam e interpretam a realidade (JODELET, 1989, 1996) mas, também, agem sobre ela (JODELET, 1989, 1996; SANTIAGO, 1996). Esta acção traduz-se nas experiências, comportamentos, práticas, interacções e comunicação que os actores desenvolvem, quotidianamente, nos diferentes contextos sociais em que se inserem (DE SÁ, 1994; JODELET, 1996). Enquanto indissociáveis destas importantes funções práticas, cognitivas e sociais (DE SÁ, 1994; JODELET, 1996), as representações concorrem, em última instância, para a construção social dessa mesma realidade. (JODELET, 1996)

O carácter abrangente e o alcance prático da proposta conceptual de Jodelet fazem com que esta seja considerada, no âmbito do presente estudo, como a mais adequada à análise das representações que os estudantes constroem sobre a avaliação das instituições. Com base nesta proposta, é possível definir o conceito de representações estudantis da avaliação como circunscrevendo as formas de conhecimento, sobre este "objecto" particular, elaborado pelos estudantes enquanto actores de um contexto social e institucional específico, e com a capacidade para influenciar as práticas que sustentam os processos avaliativos.

Por outro lado, com base em Moscovici (1976), é possível perspectivar as representações sociais como compreendendo múltiplas dimensões ou elementos 
constitutivos, simultaneamente cognitivos, motivacionais e atitudinais, que dão conta do seu sentido e significado (MOSCOVICI, 1976). O mesmo equivale a dizer, para o caso das representações elaboradas pelos estudantes, que estas expressam, na prática, um conjunto de conhecimentos, informações e atitudes destes actores sobre os diferentes aspectos da avaliação, ao mesmo tempo que comportam, também, uma determinada extensão dos significados que the são atribuídos.

Concretamente no que respeita às atitudes, estas constituem a dimensão mais dinâmica das representações sociais. As atitudes compõem a via pela qual as representações se ligam à acção, traduzindo uma orientação global e uma predisposição para agir relativamente aos objectos ou situações representados (SANTIAGO, 1989, 1996). Em última análise, a atitude integra a componente da representação responsável por congregar, num acto concreto, as informações, imagens, significados e juízos, associados a um objecto, que formam a estrutura e conteúdo da sua representação (BERGMAN, 1998; SANTIAGO, 1996). Definida deste modo, a componente atitudinal da representação permite dar conta do conjunto relativamente estável de avaliações, apreciações, disposições ou orientações subjectivas, mais ou menos positivas, ou mais ou menos concordantes, que os actores manifestam face aos objectos sociais, e que influem nas suas predisposições para agir ou comportar-se relativamente aos mesmos (SANTIAGO, 1996). Deste modo, as atitudes permitem prever ou antecipar as acções ou comportamentos dos actores sociais.

Tendo como pano de fundo esta conceptualização, é possível, pois, considerar que as atitudes constituem um elemento central na compreensão do modo como os estudantes se situam face à avaliação das instituições de ensino superior e, concomitantemente, a representam. Torna-se possível argumentar, nesta lógica, que a orientação atitudinal dos estudantes está directamente ligada à validade, às finalidades e ao carácter que atribuem à avaliação, dependendo da legitimidade e pertinência que lhe reconhecem enquanto dispositivo de regulação das instituições.

Neste contexto, é possível, ainda, assumir que as atitudes dos estudantes face à avaliação são mediadas, quer institucionalmente, quer por outros actores. Esta mediação reflecte-se na reprodução (pelo menos parcial) dos sistemas atitudinais pré-existentes, traduzindo uma maior ou menor valorização da avaliação. Além destes sistemas, há que realçar, contudo, a preponderância, na formação das atitudes dos estudantes, das experiências institucionais concretas que estes detêm no campo da avaliação. Neste domínio, as experiências positivas podem associar-se a atitudes igualmente positivas em relação ao processo avaliativo. 


\section{METODOLOGIA}

Com o intuito de apreender as configurações que moldam as atitudes dos estudantes face à avaliação das instituições (significada, neste contexto, como a avaliação dos cursos de graduação), empreendemos um estudo qualitativo ${ }^{2}$ que assume como objecto de estudo as representações que estes actores elaboram sobre este processo institucional específico.

Usando como instrumento qualitativo de recolha de dados a entrevista semi-estruturada, este estudo tem como amostra 102 estudantes de graduação de duas universidades Portuguesas ( $\mathrm{X}$ e Y) que congregam, simultaneamente, os subsistemas universitário e politécnico (Tabela 1).

Tabela 1. Distribuição da amostra de acordo com a universidade de proveniência (X e Y) e respectivo subsistema de ensino superior

\begin{tabular}{rccc}
\hline \multirow{2}{*}{ Subsistema } & \multicolumn{2}{c}{ Universidade } & Total \\
\cline { 2 - 3 } & $\mathbf{X}$ & $\mathbf{Y}$ & \\
\hline Universitário & 43 & 23 & 66 \\
\hline Politécnico & 10 & 26 & 36 \\
\hline Total & $\mathbf{5 3}$ & $\mathbf{4 9}$ & $\mathbf{1 0 2}$ \\
\hline
\end{tabular}

Tabela 2. Distribuição da amostra de acordo com o tipo de sub-amostra (A e B)

\begin{tabular}{|c|c|c|c|}
\hline \multirow{2}{*}{ Sub-amostra } & \multicolumn{2}{|c|}{ Universidade } & \multirow{2}{*}{ Total } \\
\hline & $\mathbf{x}$ & $\mathbf{Y}$ & \\
\hline A & 38 & 35 & 73 \\
\hline$B$ & 15 & 14 & 29 \\
\hline Total & 53 & 49 & 102 \\
\hline
\end{tabular}

Estes estudantes distribuem-se por duas sub-amostras - A e B (Tabela 2) definidas de acordo com dois principais critérios: o ano académico frequentado e a participação nos órgãos colegiais das instituições - participação institucional - e/ou nas associações académicas de estudantes ou outras instâncias académicas - participação académica. Deste modo, a sub-amostra A é composta por estudantes que frequentam desde o $2^{\circ}$ ao $4^{\circ}$ ano académico e sem participação institucional ou académica, enquanto a sub-amostra B é constituída por estu-

2 Este estudo foi desenvolvido no contexto de uma investigação doutoral intitulada "Representações Estudantis da Avaliação das Instituições de Ensino Superior Público", da autoria da primeira autora deste trabalho, sob orientação científica dos dois outros autores. 
dantes a frequentar qualquer ano académico, excepto o $1^{\circ}$, e com participação institucional e/ou académica.

Os dados recolhidos através das entrevistas a estas sub-amostras de estudantes foram sistematizados com recurso à técnica de análise de conteúdo temático/categorial (BARDIN, 1995), coadjuvada, por seu turno, pelo programa informático QSR NUD*Ist. Com base em estratégias empíricas de análise, combinando, simultaneamente, métodos abertos e fechados, a análise de conteúdo dos dados envolveu a construção de uma grelha de análise estruturada em temas reagrupados em categorias, e estas, por sua vez, organizadas em diferentes dimensões de análise.

No final, foram definidas quatro dimensões de análise traduzindo os elementos centrais que estruturam o conteúdo das representações estudantis da avaliação: (1) A 'Atitude' - que delimita as posições subjectivas dos estudantes em relação à implementação da avaliação (em sentido geral, i.e. enquanto mecanismo de regulação e controlo institucional); (2) A 'Informação' - que se refere ao conhecimento e informação dos estudantes sobre a avaliação das instituições (em sentido estrito, ou avaliação de cursos); (3) A 'Conexão com a Acção' - que traduz a experiência e a predisposição dos estudantes para se envolverem na avaliação das instituições (em sentido estrito); e (4) 'O Campo das Representações Estudantis da Avaliação' - que se refere ao conteúdo e extensão das representações estudantis da avaliação (em sentido geral ou estrito).

O presente trabalho sustenta-se, especificamente, na primeira destas dimensões de análise - a dimensão 'Atitude' - mediante a qual se pretende identificar a posição geral dos estudantes em relação à implementação da avaliação ao nível das instituições de ensino superior. A assunção que lhe está subjacente é a de que a componente atitudinal das representações estudantis permite dar conta do posicionamento, mais ou menos favorável, revelado pelos estudantes, quanto ao conceito de avaliação e às diferentes modalidades que a formalizam ao nível das instituições. Deste modo, esta dimensão tem por objectivo, não tanto esmiuçar o conteúdo das representações dos estudantes, mas circunscrever as disposições por eles manifestadas em relação quer à avaliação em geral - enquanto instrumento de controlo do desempenho e da qualidade do ensino superior, direccionado às diversas dimensões do funcionamento do sistema $\mathrm{e}$ das instituições - quer à avaliação em sentido mais estrito - correspondendo ao conjunto de processos mais específicos, compreendidos pela sua implementação ao nível dos cursos.

Partindo do pressuposto de que a orientação destas disposições se encontra directamente ligada ao reconhecimento e à tomada de posição face à validade $\mathrm{e}$ 
credibilidade da avaliação, esta dimensão inclui três categorias - 'legitimidade', 'finalidades instrumentais' e 'modalidades' da avaliação - que procuram traduzir as atitudes dos estudantes em relação a estes mesmos atributos. A primeira categoria diz respeito à legitimidade, pertinência e significados atribuídos pelos estudantes à avaliação em sentido geral ou estrito. A categoria 'finalidades instrumentais' refere-se ao intuito ou objectivos atribuídos pelos estudantes à avaliação (em sentido geral ou estrito) - avaliar porquê ou para quê? - bem como às áreas de actividade e/ou funcionamento (do sistema, das instituições e/ou das unidades orgânicas) por eles percebidas como susceptíveis de constituir o seu "alvo" preferencial - avaliar o quê?. Por último, a categoria 'modalidades de avaliação' dá conta, na perspectiva dos estudantes, do direccionamento ou enfoque da avaliação (em sentido geral ou estrito) nos processos e/ou nos resultados do sistema de ensino superior, e/ou das instituições, e/ou das unidades orgânicas. Neste contexto, a avaliação pode assumir diversas modalidades, variando desde uma mais informativa (recolha e difusão de informação), ou formativa (indução de análise reflexiva), até outra, punitiva (implementação de recompensas/sanções com base nos resultados avaliativos), passando por outras modalidades, como a avaliação de controlo ou regulação (instrumento de accountability $^{3}$ ) e a avaliação comparativa (ranking e competição interinstitucional).

Com base nas categorias de análise que acabámos de circunscrever procedese, na parte subsequente deste trabalho, à análise, interpretação e discussão dos dados empíricos possibilitando a caracterização da dimensão atitudinal das representações estudantis da avaliação das instituições. Num primeiro momento, através da análise mais global do significado assumido pelas atitudes dos estudantes, procede-se ao "mapeamento" das configurações comuns manifestadas nas suas representações, independentemente dos seus subgrupos amostrais. Num segundo momento, na parte dedicada, também, à síntese conclusiva dos principais resultados do estudo, e com o intuito de a complementar, realiza-se uma abordagem comparativa das representações estudantis, mediante a qual se procura apreender as clivagens observadas na sua significação. Esta abordagem, centrada exclusivamente na detecção das diferenças mais expressivas manifestadas nas disposições dos estudantes face à avaliação, é realizada em função das seguintes variáveis: o subsistema de ensino superior que os estudantes integram (universitário ou politécnico); o tipo de participação institucional e/ou académica (ao nível dos órgãos colegiais das instituições e/ou das associações

3 O facto de a tradução portuguesa de accountability poder ter vários significados (prestação de contas, responsabilização, demonstração de valor), optámos por recorrer, no contexto do presente trabalho, ao termo original. 
académicas) em que estão envolvidos; e a experiência acumulada em relação à implementação institucional da avaliação.

\section{A DIMENSÃO ATITUDINAL DAS REPRESENTAÇÕES ESTUDANTIS DAAVALIAÇÃO}

\section{A Legitimidade da Avaliação}

Com base na análise dos discursos dos estudantes, é possível constatar que estes expressam, em geral, posições manifestamente favoráveis em relação à noção de avaliação e à sua implementação no âmbito do ensino superior (ES). A avaliação é percepcionada como promovida, essencialmente, pelo Estado, ou por outras entidades externas (não especificadas), e direccionada, sobretudo, para as instituições de ensino superior (tanto públicas, como privadas), ainda que mencionada, também, embora de modo menos sistemático, a pertinência de se centrar na aferição do sistema. Assim configurada, a avaliação é concebida como um dispositivo abrangente, que compreende a globalidade do funcionamento, desempenho e actuação das instituições. Independentemente desta abrangência, é enfatizada, contudo, por alguns estudantes, a necessidade de escrutinar certas esferas institucionais, em particular as constituídas pela docência (formação pedagógica dos docentes), os cursos (qualidade e estrutura curricular) e o ensino/educação.

Neste contexto, a avaliação é representada como um procedimento "necessário", essencial ao normal funcionamento das instituições e que, enquanto tal, não deve ser olhado por estas como uma ameaça, ou um elemento destabilizador, mas como algo "natural" e, inclusive, uma "mais-valia".

Além de aceite com relativa naturalidade, a avaliação constitui, para a maioria dos estudantes, um dever das instituições, uma obrigação a que estas devem estar sujeitas, não só porque gozam de autonomia face ao Estado, mas também, em especial, porque prestam um "importante serviço" público, educativo e formativo, à sociedade. Percepcionada enquanto um "dever" institucional, a avaliação surge como um instrumento específico através do qual as instituições prestam contas e se responsabilizam, perante o Estado, os estudantes e a sociedade, pela qualidade do seu desempenho e resultados. Neste sentido, os estudantes parecem reproduzir posições que, de alguma forma, endossam o conceito de Estado Avaliador (AFONSO, 1998; DILL, 1998; NEAVE, 1988; NEAVE 1998; NEAVE; VAN VUGHT, 1994), articulado com o discurso normativo sobre a avaliação, centrado nas noções de accountability e de consumo dos serviços educativos. (AMARAL; ROSA, 2004; HUISMAN; CURRIE, 2004; NEAVE, 1998) 
De alguma forma, este conjunto de posições assumidas pelos estudantes não difere, substancialmente, do que foi observado em outros estudos (LEITE et al., 2006; 2007), que mostram que as atitudes estudantis favoráveis à avaliação se apoiam na sua percepção como um mecanismo legítimo de controlo, regulação e responsabilização pública das instituições.

Embora reconhecida como podendo implicar, por vezes, efeitos contraditórios, ou menos vantajosos para as instituições (depreciação da sua imagem "social" e sua sujeição a pressões externas), em especial quando os seus resultados não são positivos, ou os parâmetros em que se sustenta não se adequam às especificidades da realidade institucional, a avaliação continua, porém, a constituir um dispositivo de controlo e regulação legitimado pelos estudantes. Esta legitimação parece estar ligada à sua concepção como um importante instrumento de auscultação da "comunidade" estudantil, em particular dos juízos que esta formula sobre o funcionamento e o "projecto futuro" das instituições; como um processo que questiona a "imobilidade" destas face às mudanças externas; e, sobretudo, como um instrumento crucial de promoção e garantia da sua melhoria e qualidade. $\mathrm{O}$ incremento qualitativo das instituições reflecte-se, directamente, na relação com o meio em que estão inseridas, o que acaba por traduzir-se numa maior capacidade para atrair novos estudantes, de promover a empregabilidade dos graduados ou, ainda, de "construir", quer interna (para os estudantes), quer externamente, uma imagem de qualidade, "valor", "credibilidade" e "rigor".

Este discurso sobre a avaliação não deixa, no entanto, de constituir um eco do discurso político que, recorrentemente, enfatiza a qualidade como "objecto" último da sua legitimidade (AMARAL; ROSA, 2004; DAVIES, 2003; KELLS, 1992; NEAVE; VAN VUGHT, 1994; PINTO; HEIZEN; DE MELO, 2005; ROSA, 2003; SANTIAGO, 1999). Porém, a pertinência e a validade da avaliação parecem depender, na perspectiva dos estudantes, da observância de certos critérios, ou requisitos fundamentais, conectados com o modo como a mesma se desenvolve ao nível das instituições e como estas a percepcionam e com ela se relacionam. Um destes critérios consiste na imparcialidade e independência da avaliação face a interesses e poderes instituídos. Neste âmbito, a sua componente externa - avaliação externa - é, de certo modo, representada como garantia do seu rigor, seriedade e neutralidade face a interesses corporativistas.

De facto, a avaliação externa parece assumir uma especial relevância para os estudantes, constituindo-se como um instrumento privilegiado da apreciação das decisões e das práticas institucionais, em especial ao nível dos cursos. Embora perspectivada como necessariamente apoiada num conhecimento aprofundado 
da realidade institucional, a avaliação externa é, igualmente, percepcionada como um meio de superar as supostas insuficiências da auto-avaliação. Entre estas insuficiências, os estudantes destacam, em particular, a sua instrumentalização por interesses e poderes instituídos ou, ainda, a subjectividade de que se pode revestir, tendo em atenção o facto de ser empreendida, internamente, por "alguém da casa".

Talvez devido ao carácter objectivo e independente que lhe é imputado, a avaliação externa é, ainda, considerada como o instrumento, por excelência, que mais se adequa à identificação de problemas institucionais e à concomitante definição de estratégias que visam a sua resolução. Tal não invalida, porém, o reconhecimento, por alguns estudantes, da importância da auto-avaliação como exercício institucional de auto-conhecimento, reflexivo e crítico. Neste caso, mais do que a primazia da avaliação externa sobre a interna (auto-avaliação), a ênfase é colocada na necessária complementaridade destas duas fases distintas do processo avaliativo.

Além da imparcialidade e independência, os estudantes referem, igualmente, como requisitos necessários da avaliação: a sua afirmação como um processo sistemático (periódico ou contínuo), sustentado em critérios, métodos e parâmetros coerentes e uniformes para todas as instituições; a rotatividade dos membros que integram as equipas (internas e externas) de avaliação; o conhecimento prévio, por parte destas equipas (em especial, das de avaliação externa), das especificidades de cada uma das instituições avaliadas; ou, ainda, o suporte financeiro do Estado, ou de outras entidades externas às instituições, no desenvolvimento dos processos avaliativos.

A pertinência da implementação da avaliação depende, ainda, do ponto de vista dos estudantes, da verificação de certas condições institucionais e organizacionais. Uma das mais valorizadas refere-se à institucionalização e promoção de uma "cultura" de avaliação no interior das instituições, reflectidas na integração deste processo nas suas práticas quotidianas, ou na criação de estruturas e mecanismos permanentes e especializados responsáveis pelo seu acompanhamento sistemático. Outros requisitos mencionados neste âmbito, expressam a necessidade de a avaliação dever provocar consequências "práticas" no campo institucional, e de a comunidade académica ter de estabelecer um consenso generalizado quanto aos critérios e parâmetros que a sustentam e aos significados dos seus resultados.

Apesar de percepcionada, globalmente, de forma positiva, a avaliação é, contudo, alvo de algumas críticas por parte de uma minoria de estudantes. Estas críticas ligam-se, em particular, ao não reconhecimento do processo 
como dotado de alguns dos requisitos explicitados anteriormente, conectados com a sua legitimidade e pertinência. Neste âmbito, os estudantes salientam, sobretudo, a ausência de uma "cultura" de avaliação, o carácter não sistemático e superficial por esta assumido, e a não produção de consequências objectivas a partir dos seus resultados.

Além de enfatizarem a necessidade de ligação da avaliação a efeitos práticos, estas críticas evidenciam a contradição existente entre as representações que os estudantes tecem sobre o modo como a avaliação é institucionalizada e as representações das próprias instituições sobre esta mesma institucionalização. Assim, embora as instituições pareçam ter assumido e desenvolvido uma cultura de avaliação (traduzida, por exemplo, na formalização de sistemas e práticas de escrutínio e garantia da qualidade) (AMARAL; ROSA, 2004; ROSA; TAVARES; AMARAL, 2006), tal não produziu, ainda, um impacto duradouro, ou consistente, nas percepções de muitos estudantes.

Por último, são também sublinhadas, como facetas negativas da avaliação, o seu enfoque primordial nas questões relacionadas com o ensino, o insuficiente envolvimento institucional dos estudantes no processo ou, ainda, a possibilidade de os seus resultados darem origem à ordenação hierárquica das instituições (rankings).

Algumas das críticas anteriormente sistematizadas estão, também, presentes nos discursos do grupo bastante restrito de entrevistados que se reporta, concretamente, à avaliação de cursos (graduação). Tal é o caso, por exemplo, do incipiente envolvimento dos estudantes neste processo, justificado pela distância deste em relação aos seus interesses; da relativa ausência, inconsistência, ou morosidade na observação de resultados práticos a partir da sua implementação; e da aparente inadequação dos critérios e parâmetros que o sustentam, ou da sua aplicação indiscriminada, sem consideração pelas especificidades institucionais.

Outras dimensões da avaliação de cursos, também alvo de apreciações menos positivas por parte deste grupo minoritário de estudantes, consistem no seu enfoque prioritário nos cursos, "ocultando" aspectos chave, de âmbito mais específico, como a componente pedagógica (relação, métodos e formação pedagógica dos docentes), ou mais geral, relacionados com a situação "real" da instituição; ou, ainda, o modo como se organiza a sua implementação auto-avaliação e avaliação externa -, percepcionado como deturpando a sua imparcialidade e interferindo na sua abrangência e eficácia.

Ainda neste registo crítico, é possível detectar, nos discursos de alguns estudantes, uma certa renitência quanto à forma assumida pela coordenação política da avaliação de cursos. Esta postura é traduzida na manifestação de 
posições favoráveis em relação à substituição do órgão responsável, até muito recentemente, por essa coordenação - o CNAVES - por uma agência nacional de avaliação e acreditação, cuja criação havia sido, de facto, promulgada por altura da realização das entrevistas (Decreto-Lei 369/2007), como forma de superar as supostas insuficiências manifestadas pelo processo avaliativo.

Em certos casos (igualmente pouco representativos), a assunção de uma postura mais crítica pelos estudantes, parece relacionar-se, também, com a defesa da substituição da avaliação de cursos por um outro formato avaliativo: a avaliação institucional. Representada como um "estudo" aprofundado da dinâmica global de funcionamento das instituições, esta modalidade de avaliação surge, neste âmbito, como a única capaz de proporcionar um conhecimento amplo e detalhado sobre as fragilidades e insuficiências institucionais e, por inerência, de contribuir para a sua resolução.

Com base na análise das posições críticas assumidas em relação, concretamente, à avaliação de cursos, algumas das quais coincidentes com as sistematizadas noutros estudos (AMARAL, 2003; POLIDORI, 2000), é possível argumentar que, apesar de um certo alinhamento com a noção "política" da avaliação e da sua implementação, os estudantes parecem questionar algumas das componentes basilares que configuraram o sistema avaliativo nacional por cerca de uma década. Neste âmbito, os estudantes demonstram uma relativa consonância com as medidas legislativas que haviam sido recentemente adoptadas (Lei 38/2007 e Decreto-Lei 369/2007), destinadas a alterar o locus de coordenação do modelo avaliativo - substituição do CNAVES pela Agência de Avaliação e Acreditação - ou o seu enfoque - alargamento da avaliação a um âmbito institucional.

\section{FINALIDADES INSTRUMENTAIS DA AVALIAÇÃO}

É possível identificar, nas posições dos estudantes, uma tendência para associar a avaliação a uma dupla finalidade, expressa, por um lado, na aferição do sistema e das instituições e, por outro, no incremento das suas estruturas, processos e actividades. Contudo, é de realçar uma maior propensão para a representação da avaliação como um dispositivo susceptível de realizar estas últimas funções, em especial, ao nível institucional. De facto, apesar de uma relativa dispersão das referências discursivas a elementos situados em diferentes níveis do ES, a maioria concentra-se, mais recorrentemente, no funcionamento e organização das instituições. Esta orientação do discurso vai ao encontro de uma das conclusões permitidas pela categoria de análise 'legitimidade', que 
aponta para a existência de uma representação da avaliação como devendo ser organizada em torno da sua abrangência institucional (funcionamento global das instituições).

Assim, no que respeita ao enfoque da avaliação (avaliar o quê?), este situase, para a maioria dos estudantes, na instituição como um todo. São, porém, preferencialmente mencionados, enquanto aspectos da vida institucional mais susceptíveis de serem escrutinados: a gestão, nomeadamente a gestão financeira; a qualidade, incluindo a das infra-estruturas, recursos, serviços e pessoal não docente; e a eficiência, eficácia, desempenho e resultados institucionais.

Embora de modo mais residual, são, ainda, sublinhados, nos discursos, outros elementos relacionados com a actividade global das instituições, tais como: o cumprimento da sua missão e objectivos; a vertente "humana" da formação proporcionada e a "oferta" de cursos; a "produtividade" institucional, mensurável em termos do "sucesso" escolar dos estudantes; o ratio qualidade/ quantidade de graduados por ano lectivo; a relação institucional com o exterior, em especial, com o sector económico (empregadores e tecido empresarial) e as estratégias de promoção da empregabilidade dos graduados; e, por fim, o ambiente interno da instituição, em particular a coordenação entre as diferentes unidades orgânicas e serviços e as condições de trabalho, satisfação e bem-estar dos diferentes grupos institucionais.

A centralidade assumida por estes elementos reflecte, até certo ponto, a existência, nos discursos, de uma forte influência de alguns dos pressupostos da retórica managerialista sobre o ES e a avaliação: a ênfase na gestão e racionalidade económica, na eficiência, eficácia, produtividade e nos desempenhos (AFONSO, 1998; SANTIAGO, 2005). Contudo, os discursos dos estudantes assumem, neste campo, uma configuração híbrida. Neles é possível observar, igualmente, a presença de referências às dimensões mais "humanistas" da educação, alinhadas com um conceito mais "tradicional" do ES, próximo das concepções humboldtianas e newmanianas sobre a formação da mente e do carácter. (BARNETT, 1990; FARIA, 2003; MAGALHÃES, 2004; NYBOM, 2002)

Subsequentes ao enfoque institucional da avaliação, outros domínios são, no entanto, eleitos pelos estudantes como constituindo "objecto" do seu escrutínio. Tal é o caso, por exemplo: do ensino e da docência, com uma ênfase especial na qualidade do ensino e dos docentes (qualificações, competência e relação pedagógicas); da formação facultada pelas instituições, sobretudo, da sua qualidade, carácter "prático" e adequação às exigências do mercado de trabalho, traduzida no seu contributo para a inserção profissional dos graduados; dos cursos em geral, com enfoque primordial na sua estrutura curricular ou, ainda, na qualidade da componente pedagógica; da "condição" institucional e 
académica dos estudantes, em particular, o seu sucesso académico (razões da aprovação/retenção, por exemplo), os apoios (socioeconómicos, educativos) de que beneficiam ou, ainda, a sua satisfação e bem-estar.

Quanto às suas finalidades (avaliar porquê? ou para quê?), a avaliação tende a ser representada como um processo que contribui, essencialmente, para a melhoria e garantia da qualidade de determinadas dimensões institucionais. Uma das mais centrais é constituída, sem dúvida, pela qualidade da instituição em geral, que permite que esta demonstre o seu "valor" e prestígio.

As restantes dimensões institucionais percepcionadas pelos estudantes como igualmente susceptíveis de serem melhoradas pela avaliação são, de certo modo, coincidentes com as representadas como devendo ser submetidas ao seu escrutínio e replicam, também, alguns dos campos dominantes à volta dos quais os guiões da avaliação, então em vigor, estavam estruturados: qualidade pedagógica; relação institucional com o exterior; inserção profissional dos graduados; gestão e eficiência; ambiente, informação e comunicação organizacionais; infra-estruturas e recursos; e capacidade institucional para a obtenção de financiamento externo. Estes campos coincidem, grosso modo, com os que são enunciados nos estudos de Leite e outros $(2006,2007)$ e Polidori (2000), como sendo os que são percepcionados pelos estudantes como passíveis de serem beneficiados pela avaliação, em termos de incremento qualitativo.

O sistema de ES constitui, na visão dos estudantes, a esfera que, logo após a institucional, mais benefícios recolhe da avaliação. A este nível, o incremento da qualidade manifesta-se, especialmente, na uniformização ou padronização do ensino superior e das políticas que visam este sector, e numa maior racionalização do sistema (em termos do ratio cursos/instituições, do tipo de "oferta" educativa, ou dos recursos docentes), acompanhada por uma maior especialização das instituições por áreas científicas.

Os estudantes sublinham, ainda, o contributo da avaliação para a qualidade da formação que recebem nas instituições e, como reflexo desta, para a promoção da sua futura empregabilidade. Neste âmbito, a avaliação é considerada como um processo que pode auxiliar as instituições no desenvolvimento de estratégias destinadas a promover a inserção dos graduados no mercado de trabalho. A centralidade atribuída à possibilidade de a avaliação cumprir este papel, reflecte, em certa medida, o ambiente "vocacionalista" dominante nos discursos políticos sobre os currículos do ES. O carácter utilitarista da educação superior (LEITE et al., 2007), ou a "mercantilização" dos cursos (ESTANQUE; NUNES, 2003), surgem, provavelmente, significados, como o reflexo da "crise do desemprego" que caracteriza as sociedades actuais? (PAIVANDI, 2006), 
conjugada com a perda do capital simbólico e do "valor de troca" dos diplomas no mercado de trabalho.

\section{MODALIDADES DE AVALIAÇÃO}

A análise dos resultados das entrevistas permite observar que, além de se focarem, principalmente, nas instituições como um todo, as posições dos estudantes se desdobram pelo conjunto das lógicas avaliativas mencionadas anteriormente (vide Metodologia) - informativa, formativa, punitiva, de controlo ou regulação e comparativa. Tal equivale a dizer que a avaliação é associada não apenas a um, mas a vários propósitos simultâneos. Porém, é possível identificar uma certa tendência para a valorização (ainda que não muito acentuada) de uma modalidade de avaliação com um carácter reflexivo ou formativo, que permita à instituição um melhor auto-conhecimento das suas potencialidades e fragilidades, bem como a definição de estratégias orientadas para a manutenção ou incremento das primeiras e a resolução das últimas.

A emergência desta tendência nos discursos alinha-se com as conclusões do estudo de Leite e outros (2007), em que se sublinha a preferência dos estudantes por uma avaliação de pendor "construtivo" ou de "aconselhamento". Porém, esta preferência é, também, acompanhada, no caso dos estudantes entrevistados, pela valorização de uma modalidade de avaliação mais regulatória ou de controlo, conotada com a accountability institucional. Esta orientação das atitudes dos estudantes parece indiciar que, embora estes atribuam alguma importância a um tipo de avaliação que possibilite às instituições um melhor auto-conhecimento crítico, também a perspectivam como devendo funcionar como um mecanismo de controlo hierárquico.

Alguns estudantes consideram, inclusive, que este controlo deveria ser tão "apertado" como aquele que, supostamente, se verifica ao nível dos restantes sistemas de ensino (não superior), sustentado na inspecção das instituições. Reconhecem, todavia, que a transposição desta inspecção para o nível do ES se confrontaria, provavelmente, com alguns obstáculos suscitados pelas suas especificidades.

Curiosamente, as referências a um tipo de avaliação com um carácter meramente informativo ou, num outro registo, com um carácter comparativo e classificatório, embora menos frequentes que os tipos anteriores, apresentam um padrão discursivo bastante semelhante. No primeiro caso, os estudantes consideram que a informação recolhida pela avaliação deve visar a divulgação pública da qualidade e do modo de funcionamento da instituição, simultaneamente junto de actores internos e externos (governo, famílias e sociedade em 
geral). No segundo caso, a comparação interinstitucional, possibilitada pelos resultados da avaliação, é percepcionada, essencialmente, como um modo de distinguir (nacional ou internacionalmente) e hierarquizar as instituições pela sua qualidade.

Os resultados da avaliação podem, ainda, servir de fundamento a uma "saudável" competição entre as instituições, à captação de financiamentos e de estudantes e, inclusive, à promoção de um melhor desempenho, especialmente no que respeita à qualidade do ensino. Embora com uma expressão mais reduzida no conjunto de posições dos estudantes, a assunção da avaliação como um dispositivo para marcar a "diferença" entre as instituições, não deixa de constituir um reflexo do ambiente que, crescentemente, tem envolvido a retórica sobre a instrumentalidade institucional e social dos processos avaliativos (LEITE et al., 2006, 2007; SANTIAGO, 2005). Apoiada na avaliação, a entrada das instituições no "jogo" da competição interinstitucional favorece a eficiência e a eficácia e contribui para estratificar o sistema através da escolha dos estudantes e das recompensas estatais.

Além disso, sempre que traduzidos num determinado posicionamento e hierarquização das instituições em rankings, os resultados da avaliação, ao serem conotados com uma certa imagem, valor e qualidade, podem não só influenciar a sua visibilidade e projecção social, como também a dos seus diplomados face ao mercado de trabalho. Porém, é de salientar que as atitudes favoráveis manifestadas pelos estudantes em relação aos rankings não são, no caso dos estudantes entrevistados, tão expressivas quanto aquelas que são reveladas, por exemplo, pelos estudantes observados nos estudos de Leite et al. (2006, 2007). Nestes, os autores concluem mais assertivamente sobre a existência, nos discursos estudantis, da manifestação de atitudes mais claramente alinhadas com a noção de hierarquização institucional e social das instituições.

Finalmente, em comparação com outras possíveis modalidades da avaliação, as atitudes dos estudantes emergem como mais manifestamente críticas e "defensivas" quando o que pode estar em causa são possíveis dimensões punitivas ou sancionatórias. Pese embora a ausência de trabalhos que permitam sustentar, conceptualmente, esta constatação, parece ser possível afirmar que as representações dos estudantes exprimindo a rejeição de uma avaliação sancionatória, podem, de algum modo, situar-se na proximidade das representações institucionais dominantes no campo.

Do mesmo modo, é possível identificar, ainda, uma certa contradição entre as atitudes assumidas pelos estudantes e a retórica política. Com base na análise de medidas legislativas recentes (Leis 1/2003, 37/2003, 49/2005 e 62/2007) e das tendências assumidas pelo Estado no controlo e regulação das instituições, 
observa-se uma ênfase crescente no princípio dicotómico das recompensas/ sanções da avaliação, sendo a esfera financeira uma das privilegiadas para o materializar.

Porém, o posicionamento face a uma avaliação de carácter sancionatório tende a assumir, nos estudantes com participação nos órgãos institucionais ou nos órgãos dirigentes associativos, uma configuração ligeiramente distinta da identificada anteriormente. Estes estudantes manifestam, na mesma linha do que é concluído por Amaral (2003), para o caso dos que integram os órgãos das associações, uma maior propensão para valorizarem uma modalidade de avaliação mais punitiva. Esta tendência (ainda que pouco marcada) expressa-se, concretamente, no facto de considerarem que os "maus" resultados da avaliação (insuficiências ao nível da qualidade institucional, dos cursos ou do ensino, por exemplo) justificam e devem conduzir ao encerramento dos cursos ou das instituições, ou que estas sejam penalizadas financeiramente (diminuição ou suspensão do financiamento público).

A assunção, por estes estudantes, de atitudes mais "extremadas" face à avaliação e ao carácter de que esta se deve revestir, talvez possa ser compreendida à luz da posição que ocupam na "arena política" do ES, susceptível de os tornar mais críticos em relação ao conteúdo, dinâmica e consequências dos processos institucionais.

\section{CONCLUSÃO: AMBIGUIDADES NAS ATITUDES DOS ESTUDANTES FACE À AVALIAÇÃO}

Terminada a discussão dos resultados globais obtidos através da análise dos discursos dos estudantes, importa, agora, reflectir sobre os seus principais significados e o que estes nos revelam acerca das atitudes manifestadas em relação à avaliação. Recorde-se que esta análise se sustenta na assunção de que estas atitudes compõem a via pela qual as representações estudantis se ligam à acção (MOSCOVICI, 1976; SANTIAGO, 1989, 1996), permitindo identificar o modo como os estudantes se posicionam relativamente à implementação da avaliação ao nível do ES e das suas instituições.

De uma forma geral, é possível concluir que a componente atitudinal das representações dos estudantes permite dar conta de um conjunto relativamente estável de posições que traduzem a aceitação da avaliação. Esta aceitação estrutura-se em torno de três principais eixos discursivos, de acordo com os quais a avaliação é representada como um dispositivo pertinente e válido da regulação das instituições: a legitimidade que lhe é reconhecida no exercício dessa mesma regulação; as finalidades instrumentais que, supostamente, realiza 
ao nível das instituições e do sistema; e o carácter que lhe é conferido no desempenho destas finalidades, traduzindo a assunção de modalidades avaliativas específicas (Figura 1).

Podem, porém, ser detectadas ligeiras diferenças nas significações produzidas pelos estudantes em relação ao modo como, em relação a cada um dos eixos definidos, representam a pertinência e validade da avaliação. Nos primeiros dois eixos, as posições que os estudantes manifestam no seu discurso reproduzem, em larga medida, os discursos externos sobre a "ideologia" e os pressupostos da avaliação. Esta emerge, assim, como uma componente "naturalizada" do processo de regulação das instituições, destinada a melhorar os seus processos e resultados e, deste modo, aumentar a eficiência, eficácia e qualidade institucional e social do ensino superior (AFONSO, 1998; AMARAL; ROSA, 2004; DAVIES, 2003; KELLS, 1992; NEAVE; VAN VUGHT, 1994; ROSA, 2003; SANTIAGO, 1999, 2005). No terceiro eixo, as representações dos estudantes são bem mais matizadas, parecendo significar a avaliação mais como um suporte ao desenvolvimento institucional, do que como um instrumento de promoção do "jogo" de recompensas/sanções, destinado a hierarquizar as instituições e a estratificar o sistema.

É, assim, possível argumentar que as atitudes dos estudantes em relação à legitimidade e às finalidades da avaliação (incluindo a avaliação de cursos), além de situadas num registo favorável, significando a sua aceitação como um processo que introduz uma "mais-valia" ao nível do ES, se sustentam na reprodução discursiva da retórica política dominante sobre o contributo deste processo para a promoção da melhoria das instituições, dos programas curriculares (cursos) e da eficiência institucional e social do sistema. Esta reprodução é, também, visível ao nível das próprias condições que os estudantes colocam à noção de legitimidade, em particular no que respeita à componente externa da avaliação, ou ao desenvolvimento, pelas instituições, de uma cultura avaliativa. Estes dois aspectos surgem percepcionados como garante da imparcialidade, objectividade e coerência do exercício avaliativo, o que não deixa de constituir um elemento da desconfiança que manifestam em relação à capacidade das instituições em se auto-regularem.

A ampla aceitação da avaliação, revelada pelas atitudes dos estudantes, constitui um dado importante para a sua naturalização, no campo do ensino superior, como um instrumento de regulação e controlo do sistema, das instituições e dos académicos (AFONSO, 1998; CORREIA et al., 2000; MAGALHÃES, 2004; NEAVE, 1988; NEAVE; VAN VUGHT, 1994). A lógica desta naturalização, em evidência na sintonia entre as razões que justificam a legitimidade e as finalidades da avaliação, que a fazem emergir como uma "ideologia" e uma 


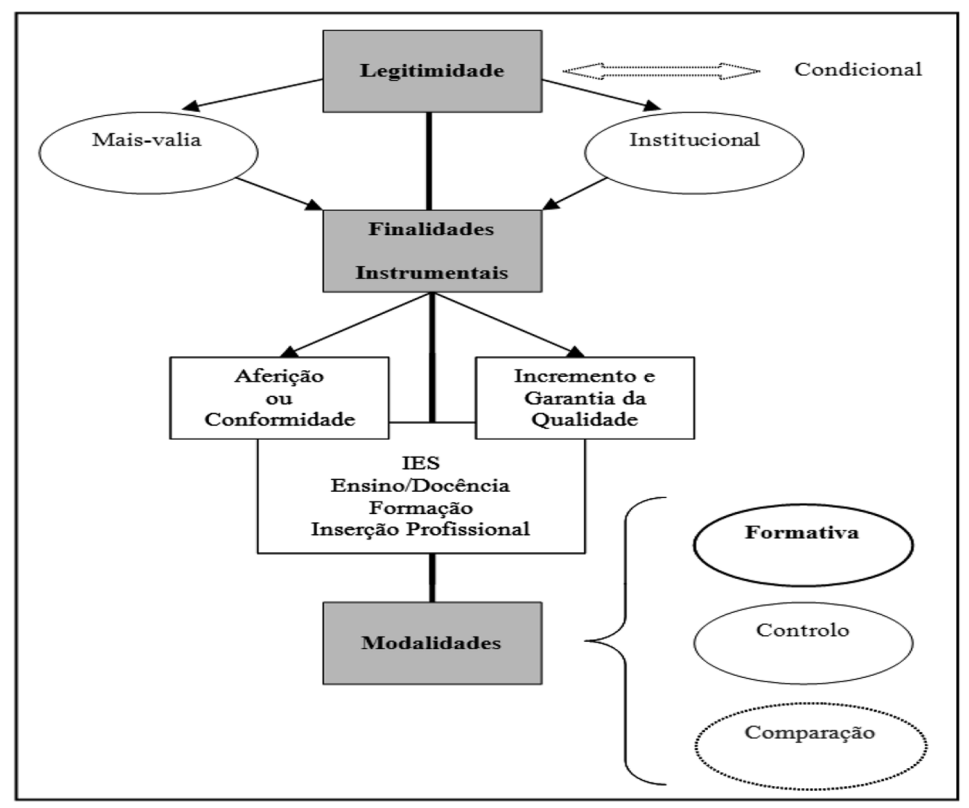

Figura 1. Elementos estruturantes das atitudes dos estudantes face à avaliação das IES

prática inquestionáveis, assume duas vertentes centrais: a aferição, traduzida na verificação da conformidade ou adaptação das instituições a um conjunto de normas e requisitos impostos, externamente, pelas políticas e medidas governamentais; e a melhoria e garantia da qualidade. Neste contexto, as finalidades da avaliação surgem situadas a três diferentes níveis, os quais, do ponto de vista dos estudantes, parecem apresentar alguma coerência: a qualidade das instituições como um todo (incluindo a sua gestão); a qualidade do ensino (cursos) e da docência; e a facilitação da empregabilidade dos graduados.

Parece ser possível argumentar, assim, que as atitudes dos estudantes face à avaliação são ditadas por razões instrumentais, pragmáticas, tendo em atenção, provavelmente, o ambiente competitivo existente, hoje em dia, no ES e as dificuldades percepcionadas sobre a inserção no mercado de trabalho. (PAIVANDI, 2006)

Contudo, uma nuance emerge no discurso dos estudantes quanto à forma de operacionalização da aferição e da melhoria da qualidade. A este nível, parece desenhar-se uma recusa de uma perspectiva sancionatória, ou coerciva, da avaliação e a valorização de uma perspectiva formativa, mais orientada para a regulação à distância, articulada com a noção de accountability. (HENKEL; VABǾ, 2000; HUISMAN; CURRIE, 2004; KELLS, 1992; MAGALHÃES, 2004; MEEK, 2003; NEAVE, 1988; ROSA, 2003; SANTIAGO, 2005) 
Apesar de, em alguns casos, a avaliação surgir significada como um instrumento destinado a produzir resultados comparativos e a própria competição interinstitucional, o discurso dominante dos estudantes apresenta algumas regularidades que permitem supor que a sua visão da avaliação, enquanto noção e conjunto de processos instituídos para controlar e regular as instituições e os cursos, se situa num registo mais "soft" do que "hard". A rejeição maioritária de uma avaliação com um carácter mais sancionatório ou punitivo permite sustentar esta hipótese. Provavelmente, este fenómeno pode ser interpretado com base na defesa discursiva que os estudantes fazem sobre a necessidade de preservar a imagem das instituições e dos cursos, estruturada em torno do prestígio social da formação e do valor dos diplomas no mercado de trabalho.

Em conclusão, as atitudes dos estudantes face à avaliação são determinadas pela legitimidade e pertinência que lhe reconhecem, atributos que parecem ser significados sob forte influência dos sistemas representacionais sociais, políticos e institucionais pré-existentes. Neste sentido, os estudantes valorizam uma configuração de avaliação que articula a sua noção política, conectada com a qualidade, accountability e controlo ou regulação, com uma noção institucional, expressa na rejeição do carácter sancionatório e na valorização da avaliação enquanto exercício auto-reflexivo.

\begin{tabular}{|c|c|c|c|c|c|c|c|}
\hline \multirow{2}{*}{\multicolumn{2}{|c|}{ Categorias e Tema }} & \multicolumn{2}{|c|}{ Sub-amostra } & \multicolumn{2}{|c|}{ Subsistema } & \multicolumn{2}{|c|}{$\begin{array}{l}\text { Experiência } \\
\text { Avaliativa }\end{array}$} \\
\hline & & $\mathbf{A}$ & B & $\mathbf{U}$ & $\mathbf{P}$ & C & $\mathbf{S}$ \\
\hline \multirow{2}{*}{ Legitimidade } & Legitimidade condicional & $\boldsymbol{0}$ & $\mathrm{O}$ & ○ & $\mathrm{O}$ & $\mathrm{O}$ & $\boldsymbol{0}$ \\
\hline & Dever ou mais-valia & 0 & 0 & $\mathbf{0}$ & 0 & O & 0 \\
\hline \multirow{2}{*}{$\begin{array}{l}\text { Finalidades } \\
\text { Instrumentais }\end{array}$} & Aferição (escrutínio) & 0 & $\mathrm{O}$ & ○ & $\mathrm{O}$ & $\mathrm{O}$ & O \\
\hline & $\begin{array}{l}\text { Incremento ou Garantia } \\
\text { da Qualidade }\end{array}$ & - & $\mathrm{O}$ & - & $\mathrm{O}$ & $\mathrm{O}$ & - \\
\hline Modalidades & Reflexiva ou Formativa & O & O & 0 & $\mathrm{O}$ & $\mathrm{O}$ & 0 \\
\hline
\end{tabular}

Quadro 1. Principais diferenças detectadas na distribuição dos estudantes pelas categorias e temas da dimensão 'Atitude'

Legenda: A - sub-amostra A; B - sub-amostra B; $\mathbf{U}$ - subsistema universitário; P - subsistema politécnico; $\mathbf{C}$ - com experiência na avaliação; $\mathbf{S}$ - sem experiência na avaliação. Concentração, nos discursos, das referências aos temas ligados à dimensão 'Atitude': • maioritária; $\bullet$ intermédia elevada; $\mathbf{O}$ intermédia baixa; O minoritária.

Tal como tivemos oportunidade de sublinhar antes (vide Metodologia), constitui nosso intento complementar, com uma abordagem comparativa, a 
análise global do significado colectivo atribuído pelos estudantes à avaliação. Recorde-se que esta abordagem comparativa se cinge à detecção e interpretação apenas das diferenças mais expressivas, deduzidas a partir das regularidades mais evidentes manifestadas nos discursos dos estudantes. Como tal, apresentamos e discutimos, em seguida, as principais diferenças no modo como os estudantes significam a 'legitimidade', as 'finalidades' e as 'modalidades' de implementação da avaliação.

Com base na leitura do quadro anterior (Quadro 1), é possível concluir que são os estudantes sem participação nos órgãos de governo e gestão e/ou nos órgãos directivos das associações académicas (sub-amostra A), pertencentes ao subsistema universitário e sem experiência ao nível da avaliação de cursos, os que insistem, principalmente, nas questões relacionadas com a noção da avaliação enquanto instrumento de aferição (das instituições no seu todo) e realçam a necessidade de esta assumir um carácter formativo ou reflexivo, conectado com o desenvolvimento e aconselhamento das instituições. São, também, estes os estudantes que, embora de modo menos sistemático que os dois anteriores temas, enfatizam, mais recorrentemente, a legitimidade condicional da avaliação (conectada com a assunção de um carácter objectivo, imparcial, consequente e externo), a actuação desta como um dispositivo de incremento e garantia da qualidade (global) e, por último, enquanto um dever e uma mais-valia para as instituições. Dada a sua relativa imprevisibilidade, sobretudo no que concerne aos estudantes do subsistema universitário, estes resultados necessitam de alguma clarificação conceptual.

Um dos elementos que maior contributo pode fornecer no sentido de possibilitar a interpretação destes resultados relaciona-se, talvez, com o contacto dos grupos identificados com a informação e com os quadros atitudinais préexistentes sobre a avaliação, nos diferentes contextos institucionais e avaliativos em que se inserem. Neste sentido, é possível argumentar que uma maior ausência de conhecimento sobre o conceito e os processos que configuram a institucionalização da avaliação, bem como de proximidade com quadros atitudinais de referência nesse campo, conduzam estes estudantes a formular representações mais idealizadas deste instrumento regulatório (enquanto exercício de aferição ligado ao desenvolvimento institucional), em comparação, por exemplo, com as que são tecidas pelos estudantes que participam nos órgãos institucionais e/ou académicos e que, simultaneamente, detém alguma experiência relativamente a essa mesma institucionalização. Sob esta lógica, é provável que estes últimos subgrupos de estudantes, pelo acesso mais directo que têm a elementos cognitivos e atitudinais mais concretos, presentes nos contextos institucionais e avalia- 
tivos, formulem representações mais "reais" do jogo da avaliação, exprimindo uma perspectiva mais "hard" sobre o que esta é, ou deve ser e, também, mais "contaminadas" por experiências mais negativas, quer sobre o desenvolvimento dos processos avaliativos, quer sobre o seu enquadramento institucional.

Deste modo, talvez seja possível assumir que, para o primeiro grupo de estudantes identificado, a avaliação seja representada como um simples processo ou procedimento burocrático, imposto a partir do exterior, com um alcance limitado, i.e., sem consequências de maior. Neste sentido, as representações destes estudantes acabam, no fundo, por reflectir o que se verificou durante os dois ciclos avaliativos desenvolvidos (1995-2000 e 2000-2005), em que a avaliação foi implementada pelas instituições como "mais" um processo que estas tiveram de assumir como obrigação, sem que tal tivesse induzido efeitos práticos visíveis. De facto, não parece ter havido, durante esse período, a intenção, nem política, nem mesmo institucional, de considerar os resultados da avaliação na definição de medidas políticas e estratégias institucionais concretas. Assim, além de mais idealizadas, as representações elaboradas por estes estudantes surgem, também, como mais "acríticas", ou "silenciadas" em relação àquilo que constituiu a realidade avaliativa durante cerca de uma década.

Por último, o facto de serem, sobretudo, os estudantes do subsistema universitário a revelar posições mais "idealizadas" e "acríticas" em relação à avaliação, talvez possa ser interpretado com base, quer na posição simbólica que as instituições universitárias ocupam no interior do sistema de ES, quer na relação que estas estabelecem com a própria avaliação. No que respeita a este último aspecto, talvez seja possível construir a hipótese de que, a implementação e naturalização mais precoces, nestas instituições, da cultura e práticas da avaliação, tenham contribuído para retirar o potencial crítico ao discurso dos estudantes sobre o processo avaliativo, favorecendo, deste modo, não só o seu distanciamento face ao mesmo mas, também, o carácter marcadamente acrítico das representações que elaboram.

Além disso, é ainda provável que estas representações sejam moldadas por uma certa "despreocupação" destes estudantes em relação aos moldes em que se processa a aferição do desempenho ou funcionamento da instituição que integram. Em primeiro lugar porque, tratando-se de instituições públicas, pressupõem que estas cumprem os requisitos, legitimados externamente, que lhes permitem "permanecer" no sistema. Por outro lado, sendo instituições universitárias, as dimensões que a avaliação visa aferir podem ser perspectivadas, pelos estudantes, como estando "asseguradas" à partida (por exemplo, a qualidade de ensino e das formações), dado o lugar privilegiado e mais pres- 
tigiante (em termos de capital simbólico, social e cultural) que, supostamente, ocupam no campo do ES. Influenciados por estas percepções, os estudantes podem assumir uma postura mais "distanciada" em relação à avaliação, que os torna, também, menos "vigilantes" e interessados nas configurações da sua implementação, nos seus resultados e nas suas consequências.

Em suma, é possível concluir que a ausência de experiência e de contacto com o "objecto" avaliação e com o locus da tomada de decisões institucionais e académicas, em particular ao nível do subsistema universitário, induz a que a dimensão atitudinal, presente nas representações estudantis da avaliação, reproduza, em parte, a retórica assertiva e "idealizada" do discurso político. Contudo, observa-se, igualmente, no discurso dos estudantes, uma dimensão "criativa" e crítica, essencialmente centrada na dimensão formativa da avaliação. Este discurso mostra que as representações dos estudantes não são unitárias nem homogéneas, mas antes contraditórias, ambíguas, difusas e, essencialmente, híbridas.

\section{REFERÊNCIAS}

AFONSO, Almerindo. Políticas educativas e avaliação educacional: para uma análise sociológica da Reforma Educativa em Portugal (1985-1995). Universidade do Minho: Centro de Estudos em Educação e Psicologia, Instituto de Educação e Psicologia, 1998.

AMARAL, Alberto. Avaliação, revisão e consolidação da legislação do ensino superior (Inquérito público: análise das respostas). Livro Branco. Coimbra: Fundação das Universidades Portuguesas, 2003. p. 1-24.

AMARAL, Alberto; ROSA, Maria. A alteração do relacionamento entre as instituições de ensino superior e o Estado e as suas consequências em termos da qualidade. In: SEMINÁRIO CONSEQUÊNCIAS INSTITUCIONAIS DA AVALIAÇÃO DAS UNIVERSIDADES PÚBLICAS, 2004, Coimbra. Comunicação apresentada... Coimbra, 2004.

BARDIN, Laurence. Análise de conteúdo. Lisboa: Edições 70, 1995.

BARNETT, Ronald. The idea of higher education. Buckingham: SHRE/ Open University Press, 1990.

BEAUVOIS, Jean-Leon.; DESCHAMPS, Jean-Claude. Vers la cognition sociale. In: GHIGLIONE, Richard; BONNET, Claude; RICHARD, JeanFrançois (Org.). Traité de psychologie cognitive. Paris: Dunod, 1990. p. 2-109. 
BERGMAN, Manfred. Social representations as the mother of all behavioral predispositions? The relations between social representations, attitudes and values. Papers on Social Representations (Textes Sur Les Représentations Sociales), Linz; Austria, v. 7, n. 1-2, p. 77-83, 1998.

CARDOSO, Sónia; CARVALHO, Teresa; SANTIAGO, Rui. From students to consumers: reflections on the marketization of portuguese higher education. In: RESUP INTERNATIONAL CONFERENCE, 1., 2007, Paris. Draft Paper presented... Paris, 2007.

CNAVES - Conselho Nacional de Avaliação do Ensino Superior. Selfevaluation report. Review of the quality assurance and accreditation policies and practices in the Portuguese higher education. CNAVES, 2006. Disponível em: < http://www.cnaves.pt/DOCS/Ava_Int/Self-Eval.Report. doc $>$. Acesso em: maio 2007.

CORREIA, Fernanda; AMARAL, Alberto; MAGALHÃES, António. Diversificação e diversidade dos sistemas de ensino superior: o caso português. Matosinhos: Centro de Investigação de Políticas de Ensino Superior, 2000.

\section{DAVIES, John. A European Agenda for Change for Higher Education} in the 21st Century. Unesco, 2003 (Working document). Disponível em: $<$ http://portal.unesco.org/en/ev.php-URL_ID $=29008 \&$ URL_DO=DO_ TOPIC\&URL_SECTION=201.html>. Acesso em: 06 abr. 2006.

DE SÁ, Celso. Sur les représentations sociales, pratiques socio-culturelles et comportement. Papers on Social Representations (Textes sur les Représentations Sociales), Linz; Austria, v. 3, n. 1, p. 1-7,1994.

DILL, David. Evaluating the 'Evaluative State': implications for research in higher education. European Journal of Education, Oxford, UK, v. 33, n. 3, p. 361-377, Sept. 1998.

ESTANQUE, Elísio; NUNES, Arriscado. Dilemas e desafios da Universidade: recomposição social e expectativas dos estudantes na Universidade de Coimbra. Revista Crítica de Ciências Sociais, Coimbra, n. 66, p. 5-44, out. 2003.

FARIA, Luísa. Universidade e cultura. Lisboa: Universidade Católica Editora, 2003. (Colecção Campos do Saber, 2).

GREEN, Diana et al. Measuring student satisfaction: a method of improving the quality of the student's experience? In: HASELGROVE, Susanne. (Ed.). The student experience. Buckingham: Open University Press, 1995. p. 100107. 
HARVEY, Lee. Student feedback. Quality in Higher Education, Oxford, UK, v. 9, n. 1, p. 3-20, Apr. 2003.

HENKEL, Mary; VABØ, Agnete. Academic identities. In: KOGAN, Maurice et al. (Ed.). Transforming higher education: a comparative study. UK: Jessica Kingsley Publishers, 2000. p. 159-1196.

HUISMAN, Jeroen; CURRIE, Jan. Accountability in higher education: bridge over trouble water? Higher Education, Netherlands, v. 48, n. 4, p. 529-551, dec. 2004.

JODELET, Denise. Epilogue. In: . Folies et représentations sociales. Paris: Presses Universitaires de France, 1989. p. 343-448.

JODELET, Denise. Représentations sociales: un domaine en expansion. In: ___ Les représentations sociales. Paris: Presses Universitaires de France, 1997. p. 31-61.

JODELET, Denise. Représentation sociale: phénomène, concept et théorie. In: MOSCOVICI, Serge (Org.). Psychologie sociale. Paris: Presses Universitaires de France, 1996. p. 357-378.

JOHNSON, Rachel; DEEM, Rosemary. Talking of students: tensions and contradictions for the manager-academic and university in contemporary higher education. Higher Education, Netherlands, v. 46, n. 3, p. 289-314, Oct. 2003.

KELLS, Herb. Self-regulation in higher education: a multinational perspective on collaborative systems of quality assurance and control. London: Jessica Kingsley Publishers, 1992.

LECKEY, Janet; NEILL, Neville. Quantifying quality: the importance of student feedback. Quality in Higher Education, Oxford, UK, v. 7, n. 1, p. 19-32, Apr. 2001.

LEITE, Denise et al. Estudantes e avaliação da universidade: um estudo conjunto Brasil-Portugal. Cadernos de Pesquisa, São Paulo, v. 37, n. 132, p. 661-686, dez. 2007.

LEITE, Denise et al. Students' representation on the influence of institutional evaluation on universities. Assessment and Evaluation in Higher Education, London, UK, v. 31, n. 6, p. 625-638, Dec. 2006.

MAGALHÃES, António. A identidade do ensino superior: política, conhecimento e educação numa época em transição. Lisboa: Fundação Calouste Gulbenkian, 2004. 
MEEK, Lynn. Introduction. In: AMARAL, Alberto; MEEK, Lynn; LARSEN, Ingvild. The higher education managerial revolution? Dordrecht: Kluwer Academic Publishers, 2003. p. 1-29.

MOSCOVICI, Serge. La psychanalyse: son image et son public. Paris: Presses Universitaires de France, 1976.

NASSER, Fadia; FRESKO, Barbara. Faculty views of student evaluation of college teaching. Assessment \& Evaluation in Higher Education, London, UK, v. 27, n. 2, p. 187-198, mar. 2002.

NEAVE, Guy. On the cultivation of quality, efficiency and enterprise: an overview of recent trends in higher education in Western Europe, 1986-1988. European Journal of Education, Linz, Austria, v. 23, n. 1-2 p. 7-23, 1988.

NEAVE, Guy. The evaluative state reconsidered. European Journal of Education, Linz, Austria, v. 33, n. 3, p. 265-284, Sept. 1998.

NEAVE, Guy; VAN VUGHT, Frans. Government and higher education relationships across three continents: the winds of change. UK: Pergamon Press, 1994.

NYBOM, Thorsten. The Humboldt legacy: reflections on the past, present and future of European higher education. In: DE CORTE, Erik. (Ed.). Excellence in higher education. London: Portland Press, 2002. p. 1-22.

OLIVEIRA, Jaime; VEIGA SIMÃO, José. Avaliação do Ensino Superior. In: MODERNIZAÇÃO DA SOCIEDADE PORTUGUESA. Coimbra: Fundação das Universidades Portuguesas, 2002. v.3: Universidade em Mudança. p. 79-130.

PAIVANDI, Saeed. As novas tendências da sociologia do estudante universitário em França. Investigar em Educação: Revista da Sociedade Portuguesa de Ciências da Educação. A Organização do Trabalho na Escola, Porto, v. 5, p. 261-298, abr. 2006.

PINTO, Marli; HEIZEN, Jadna; DE MELO, Pedro. Avaliação como compromisso e instrumento de gestão nas Instituições de Ensino Superior. Avaliação, Campinas, Sorocaba, SP, v. 10, n. 1, p. 105-120, mar. 2005.

POLIDORI, Marlis. Avaliação do ensino superior: uma visão geral e uma análise comparativa entre os contextos brasileiro e português. Porto: Universidade do Porto, 2000. 
POWELL, Anne; HUNT, Adrian; IRVING, Anne. Evaluation of courses by whole students' cohorts: a case study. Assessment \& Evaluation in Higher Education, London, UK, v. 22, n. 4, p. 397-404, Dec. 1997.

ROSA, Maria, TAVARES, Diana; AMARAL, Alberto. Institutional consequences of quality assessment. Quality in Higher Education, Oxford, UK, v. 12, n. 2, p. 145-159, Jul. 2006.

ROSA, Maria. Definição de bases estratégicas e de excelência para o desenvolvimento do ensino superior em Portugal. Aveiro: Universidade de Aveiro, 2003.

ROSA, Maria; SARAIVA, Pedro; DIZ, Henrique. Defining strategic and excellence bases for the development of Portuguese Higher Education.

European Journal of Education, London, UK, v. 40, n. 2, p. 205-221, Jun. 2005.

SANTIAGO, Rui. A escola representada pelos alunos, pais e professores. Aveiro: Universidade de Aveiro, 1996.

SANTIAGO, Rui. Contributos para a construção de um modelo de análise das representações da escola pelos alunos. Revista Portuguesa de Educação, Braga, v. 2, n. 1, p. 87-98, 1989.

SANTIAGO, Rui. O conceito de qualidade no Ensino Superior. In: ENCONTRO INA, 1., 1999, Lisboa. Acta Geral... Lisboa: Instituto Nacional de Administração, 1999. p. 355-380.

SANTIAGO, Rui. O managerialismo no campo organizacional das instituições de ensino superior. Provas de agregação apresentadas à Universidade de Aveiro em Abril de 2005. Aveiro: Universidade de Aveiro, 2005.

STENSAKER, Bjørn et al. An in-depth study on the impact of external quality assurance. In: EAIR FORUM, 30., 2008, Copenhagen. Draft paper..., Copenhagen: Copenhagen Business School, 2008.

VEIGA SIMÃO, José; MACHADO DOS SANTOS, Sérgio. Ensino superior: uma visão para a próxima década. Lisboa: Gradiva, 2002.

WESTERHEIJDEN, Don; HULPIAU, Veerle; WAEYTENS, Kim. From design and implementation to impact of quality assurance: an overview of some studies into what impacts improvement. Tertiary Education and Management, London, UK, v. 13, n. 4, p. 295-312, Dec. 2007. 